\title{
An Unusual Cause of Penetrating Abdominal Trauma: Nail Gun
}

\author{
Penetran Karın Travmasının Nadir Görülen Bir Nedeni: Çivi Tabancası
}

Bekir Sarıcık', Zeynep Özkan', Evrim Gül'2, Seyfi Emir', Fatih Mehmet Yazar', Burak Kavlakoğlu'

${ }^{1}$ Clinic of General Surgery, Elazığ Training and Resarch Hospital, Elazığ, Turkey

${ }^{2}$ Clinic of Emergency Elazığ Training and Resarch Hospital, Elazığ, Turkey

\section{ABSTRACT}

Nail guns are used for driving nails fast into concrete, wood, and metal in the contruction industry. Various injuries, such as to the extremities, thoracic region, head, and more rarely the abdominal region, from these instruments have been reported in the literature. In this article, we present a case with a nail gun penetrating injury to the abdomen. We aim to draw attention to the potential danger of these tools. It is important to take necessary precautions and well trained people who use these and similar devices which entered our lives together with developing technology and provide facilities.

Keywords: Nail gun, penetrating abdominal trauma, laparotomy Received: 26.03.2012 Accepted: 27.06.2012

\section{ÖZET}

Çivi tabancaları inşaat sanayinde betona, ahşap malzemeye ve metale hızlı bir şekilde ve kolaylıkla çiviler çakmayı sağlayan aletlerdir. Literatürde bu aletlerin hatalı kullanımına bağlı olarak ekstremiteler, toraks, kafa ve daha seyrek olarakta karın yaralanmalarına neden olan olgular mevcuttur. Bu yazıda; çivi tabancası ile karın nafiz yaralanması olan bir olguyu sunarak, bu aletlerin potansiyel tehlikesine dikkat çekmek istedik. Bu olgu, çivi tabancalarının potansiyel hayati tehlike içeren aletler içerisinde olduğunu göstermektedir ve dikkatli kullanılması gerekmektedir. Gelişen teknolojiyle birlikte hayatımıza giren ve kolaylıklar sağlayan bu ve benzeri aletlerin kullanımında kişilerin iyi eğitilmesi ve gerekli emniyet tedbirlerinin alınması önemlidir.

Anahtar Kelimeler: Çivi tabancası, penetran karın travması, laparotomi

Geliş Tarihi: 26.03.2012 Kabul Tarihi: 27.06.2012

\section{Giriş}

Çivi tabancaları inşaat sanayiinde betona, ahşap malzemeye ve metale hızlı bir şekilde ve kolaylıkla çiviler çakmayı sağlayan aletlerdir. İnşaat endüstrisinde yaygın olarak kullanılmaktadır (1). Bu aletler ateşleme mekanizmasına ve güçlerine göre yüksek hızlı ve düşük hızlı olarak iki şekilde sınıflandırılabilir. Yüksek hızlı olan çivi tabancaları patlamalı kartuş kullanarak 22 kalibrelik yivli ateşlemeli silahlar gibi çalışır, betona ve metale tek bir çivi çakabilir. Düşük hızlı olanlar ise pnömatik sistem kullanarak basınçlı havanın bir pistonu hareket ettirmesiyle çalışır ve bir seri çiviyi ahşap malzemelere başarılı bir şekilde çakabilir. Bu aletler konvansiyonel ateşli silahlar gibi balistik potansiyele sahiptir. Atış mesafesi 500 m’ye kadar olabilir ve atış hızı 100-150 m/sn olmaktadır (1-3). Bu aletler dikkatli kullanılmalıdır, uygun bir şekilde kullanılmadığında hayatı tehtid eden yaralanmalara neden olabilirler. Literatürde ekstremiteler, toraks, kafa, daha seyrek olarak da karın yaralanmalarına neden olan olgular mevcuttur (4, 5). Ülkemizde yurt dışındaki kadar sık kullanılmayan bu aletler ile yaralanma daha az görülmektedir.

Bu yazıda çivi tabancası ile karın nafiz yaralanması olan bir olguyu sunmak ve bu aletlerin potansiyel tehlikesine dikkat çekmek istedik.

\section{Olgu Sunumu}

Marangozluk yapan otuz yaşında erkek olgu iş arkadaşının kullandığı çivi tabancasından çıkan çivinin karnına isabet etmesi şikayeti ile acil polikliniğe başvurdu. Yapılan fizik muayenede genel durum orta, bilinç açık, koopere idi, sistolik kan basıncı: 


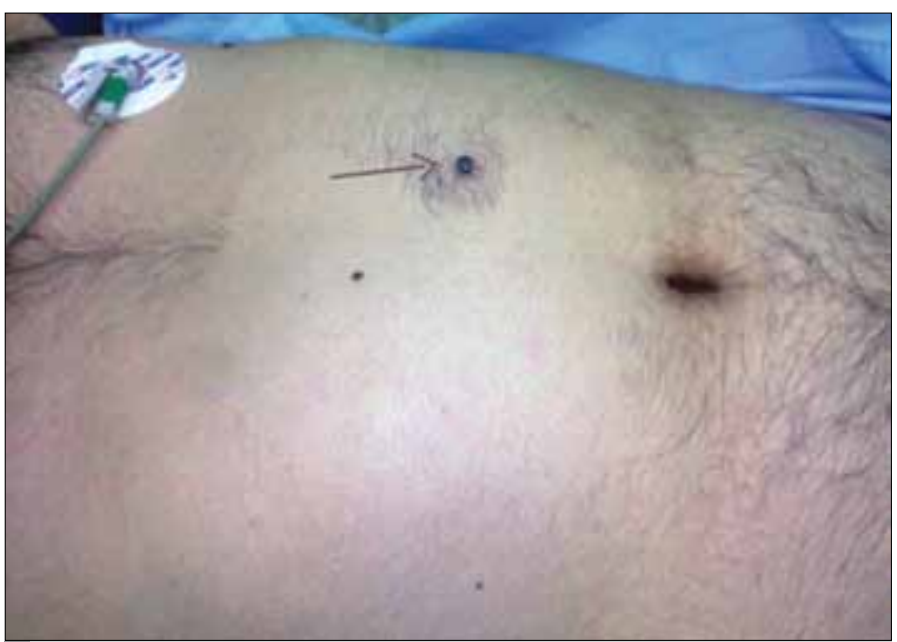

Resim 1. Çivinin (4 cm uzunluğunda) son kısmı ciltten girdiği yerde görülüyor (siyah ok ile işaretli)

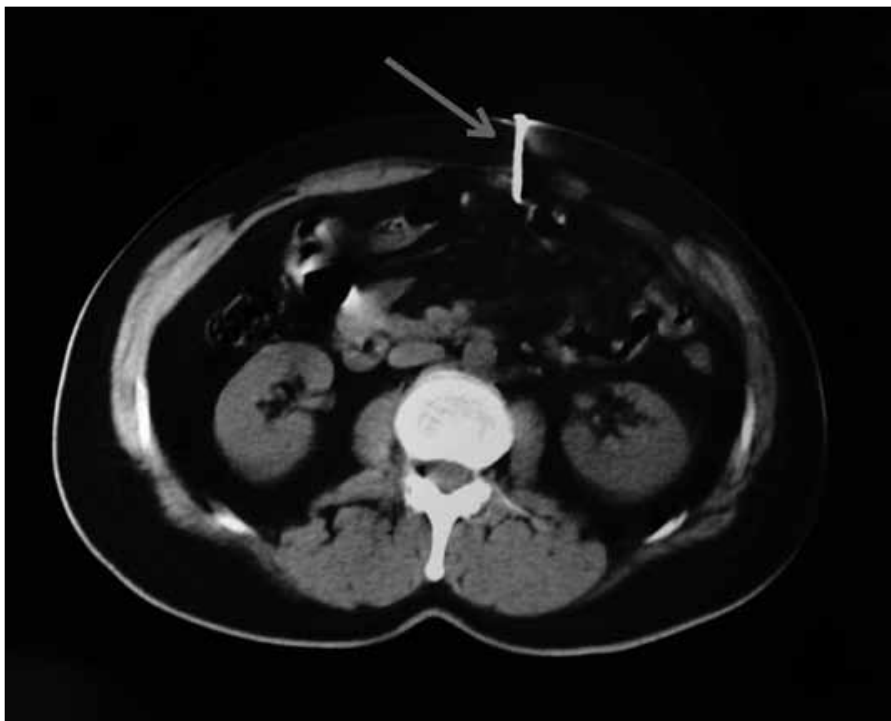

Resim 2. Batın tomografisinde çivinin gövdesi ciltten geçmiş ve ucu batın içerisinde izlenmektedir (gri ok ile işaretli)

110 mmHg, diastolik kan basıncl: 70 mmHg, nabız: 96/dakika idi. Karın muayenesinde umbilikus sol lateralinde saplanmış halde duran çivi izlendi (Resim 1). Karın sol alt kadranda hassasiyet ve rebound mevcuttu. Labaratuvar tetkiklerinde ise lökosit: 13200/mL, hemoglobin: $12,5 \mathrm{gr} / \mathrm{dL}$, trombosit: $285 \times 10^{3} / \mathrm{dL}$ idi. Hastaya çekilen ayakta batın grafisinde çivi dışında başka bir patolojik görüntü yoktu, batın tomografisinde ise çivinin yaklaşık 1 cm'lik kısmının batın içerisinde olduğu, barsak ansları arasında bir miktar serbest sıvı olduğu izlendi (Resim 2). Genel Cerrahi kliniğine yatırılarak takip edilen hastanın fizik muayene bulgularında gerileme olmaması üzerine operasyona karar verildi. Hasta bilgilendirildi, uygulanacak operasyon ve tedavi için ayrıca görüntüler için gerekli izin alındı. Yapılan laparotomide çivinin yaklaşık 1 cm'lik kısmının batın içerisinde olduğu ve batında az miktarda kanamaya sebep olduğu izlendi. İnce barsaklarda treitzden yaklaşık $100 \mathrm{~cm}$ distalde ince barsak antimezenterik yüz seroza yaralanması olduğu fakat mukozal perforasyona yol açmamış $0,3 \mathrm{~cm}$ çaplı alan izlendi. Omentumdaki yaralanmaya bağlı batın içerisinde bir miktar kanama ve omental hematom mevcuttu. Barsak serozası primer onarıldı. Çivi çıkarıldı, penetre olduğu alan serum fizyolojik ile irrige edilerek sonrasında sütüre edildi. Kanama kontrolü yapılarak operasyona son verildi. Hasta postoperatif 1. gün oral beslenmeye başlandı ve 3. gün cerrahi şifa ile taburcu edildi. Hastaya acil serviste tetanoz proflaksisi yapıldı.

\section{Tartışma}

Çivi tabancasına bağlı yaralanmalar Amerika Birleşik Devletleri'nde konut sektöründe çalışan marangozlar arasında meydana gelen tüm yaralanmaların \%14'ünü oluşturmaktadır. Tüm çivi tabancası yaralanmalarının \%90’ marangozlarda görülür ve daha çok el ve parmaklara isabet eder (5). Yaralanmaları oluş mekanizması değişkendir. Aletin kaza sonucu boşalması, aletin bakımı sırasında ateşlenmesi, çalışma ortamında doğrudan bir şekilde, çivinin sekerek isabet etmesi, parçalanması, patlayıcı kartuşun ateşlenmesi ve özkıyım girişimi gibi mekanizmalarla bu yaralanmalar olabilmektedir (1). Sunduğumuz olguda iş ortamında başkası tarafından ateşlenen çivi tabancasından çıkan bir çivi yaralanmaya sebep olmuştur.

Yaralanma sonucu oluşan doku hasarı direkt olarak çivinin giriş ve geçiş yoluna bağlı olarak ciddi hasara sebep olabileceği gibi, kurşun gibi kavitasyon etkiside yapabilmektedir çünkü belirgin bir projektil enerjiye sahiptir. Doku hasarında objenin sertliği, çivinin hızı, çivinin ya da parçalarının büyüklüğü önemlidir. Bunun yanında isabet ettiği vücut bölümüne göre yaralanmalar hayatı tehdit edebilir veya fatal olabilir. En sık ekstremiteler, özellikle de baskın olmayan el yaralanmaktadır. Bu el hastanın aleti tutmak için kullanmadığı el olup daha çok çivinin uygulanacağı malzemeyi tutmakta ve sabitlemekte kullanılır ve çivi tabancasından çıkan çivinin hedef hattında bulunur (6). Hayatı tehdit eden yaralanmalar ise daha seyrek olarak görülmektedir, bu durum daha çok kendi kendini vurma ile olur (1). Literatürde toraks, kafa, boyun ve daha seyrek olarak da karın yaralanmaları tanımlanmıştır $(4,6)$. Çivinin isabet ettiği vücut bölgesine bağlı olarak paralitik spinal kord hasarı, barsak perforasyonu, uzun kemik kırı̆̆ı, karaciğer yaralanması, görme kaybı, serebral hasar, kardiak yaralanmalar görülmüştür $(3,6)$. Çivi tabancasının kullanıldığı bir intihar girişimi olgusunda vücuda giren 8 çividen 7 tanesi baş bölgesinde, bir tanesi de karaciğer sol lobda hasara sebep olmuştur (7).

Çivi tabancasından çıkan çivi parçaları veya vücuda giren diğer yabancı cisimler röntgen filminde görülebileceği gibi bazen de görülmeyebilir. Bu olguda çivi batın grafisinde izleniyordu fakat batına nafiz olup olmadığını anlamak ve batın içi diğer patolojileri görüntülemek için batın tomografisi yapıldı. Batın tomografisinde çivinin batına nafiz olduğu, ayrıca barsak ansları arasında minimal sıvı olduğu izlendi.

Olguların tedavisinde ise penetran travmalarda uygulanan yaklaşımlar geçerlidir. Penetran karın travmalarında cerrahi eksplorasyonun endikasyonu tam çözümlenmemiş bir konudur, nonterapötik operasyonlar belirgin morbidite ve mortaliteye sebep olurlar. Laparoskopi, intraperitoneal organ yaralanmalarını saptamada yararlıdır fakat 
barsakları ve retroperitonu değerledirmede yararları sınırlıdır. Wang ve ark'ları (8) tarafından sunulan bir olguda çivi tabancasından çıkan bir çivi batın alt kadrandan penetre olmuş, yapılan tetkiklerde mesane yaralanması olduğu saptanmış bu nedenle yapılan eksplorasyonda jejunumda da çok küçük iki adet perforasyon olduğu görülerek primer onarım yapılmıştır.

Bizim sunduğumuz olguda ise çivi karın içine nafiz olarak omentum ve barsakta yaralanmaya sebep olmuştu. Hastada akut karın bulguları olması ve tomografide çivinin batın içinde izlenmesinden dolayı laparatomi kararı alınmış ve kanama kontrolü ve ince barsak seroza onarımı yapılmıştır. Cilt altı yağ tabakasının kalın olan olgumuzda, bu durumun çivinin penetrasyon derinliğini azalttığını ve hastanın lehine bir durum oluşturduğunu düşünüyoruz. Görüntüleme yöntemlerinin penetran karın travmalarında özellikle de çok büyük olmayan cisimlerle olan yaralanmalarda yanıltıcı olabilir. Bu nedenle olgunun klinik takibinin yapılması ve gerekli görüldüğünde laparatomiden kaçınılmaması gerektiğini düşünüyoruz.

Doku hasarının tedavisinde yaralanan dokunun cerrahi duruma uygun tedavinin yanında penetre olabilecek yabancı cisimler açısından da dikkatli olunmalıdır. Çiviler beraberinde yağ, kağıt, yapıştırıcı gibi maddelerini veya elbise ve cilt parçalarını yaranın derinliklerine taşıyarak o bölgeyi kontamine edebilirler. Devitalize doku, ödem ve yabancı cisimler lokal enfeksiyona sebep olabilir $(6,9)$. Biz bu olguda karın yaralanması ile ilgili tedaviyi takiben çivinin geçtiği alanı da irrige ettik ve sütüre ettik.

Sunduğumuz bu olgu, çivi tabancalarının potansiyel hayati tehlike içeren aletler olduğunu göstermektedir. Amerika Birleşik Devletleri'nde marangozlar arasında yapılan çalışmalarda çivi tabancası ile oluşan yaralanmaların sıklığı, çivi tabancasının tetikleyici mekanizmasının güvenliği ve aleti kullanmak için alınan eğitiminin süresi ilişkili bulunmuştur (10). Pnömatik ateşleme sistemi ile çalışan aletlerde iki tür tetikleyici mekanizma bulunabilmektedir. Bunlardan birincisinde tabancanın burnunda bir temas elemanı ve tetikleyiciden oluşan birleşik tetikleyici mekanizma bulunur, bu iki elemana herhangi bir anda basıldığında aletten çiviler boşalır. Buna karşılık sıralı tetikleyici mekanizma bulunduran aletlerden bir çivi atılması için tetiğe basılmadan önce aletin burnuna basılması gerekmektedir. Bu mekanizma ile çalışan aletlerden istemeden çivi boşalması zordur. Bu nedenle son yıllarda çivi tabancası üreticileri sıralı tetikleyicisi olan aletleri önermektedir (11). Dement ve ark.'ları (12) tarafından yapılan bir çalışmada bu yaralanmaların yaklaşık \%69'unun dikkatsizce ve yanlışııla aletin ateşlenmesi sonucu oluştuğu gösterilmiştir. Sıralı tetikleyicisi olan aletler kullanılarak yaralanmaların büyük oranda önlenebileceği savunulmuştur. Aleti kullanan kişilerin eğitimi ve yeterli deneyime sahip olmasının çivi tabancası yaralanmalarını önlemede önemli olduğu vurgulanmıştır. Yaralanmalar daha çok çıraklık dönemindeki marangozlarda görülmektedir ve aleti kullanmak için verilen eğitim sayesinde yaralanmaların sıklığında azalma izlenmiştir $(1,5)$. Beaver ve ark.'ları (1) bu aletleri kullanırken oluşabilecek yaralanmaları önlemek için alınacak tedbirleri şu şekilde belirtmişlerdir; IIlk olarak hiçbir çivi ta- bancası ateşlemeden önce dik düzlemden 6 dereceden daha az açıyla tutulmamalıdır. İkinci olarak çivi tabancasını ateşlemeden önce çalışılacak yüzeye bu aletle 110 Newton güç uygulamalı, havaya veya rastgele ateş etmemelidir. Son olarak ise çivinin sekmesiyle ya da sıçrayan kıymıklar nedeniyle oluşabilecek yaralanmaların önlenmesi için alete bağlı bir güvenlik kalkanı bulundurulmalıdır.

\section{Sonuç}

Gelişen teknolojiyle birlikte hayatımızda kolaylıklar sağlayan çivi tabancası gibi aletlerin kullanımında bu aleti kullanacak kişilerin iyi eğitilmesi, yeterli deneyim sağlanması, üreticiler tarafından da bu gibi aletlerin tasarımının daha az riskli olacak şekilde yapılması gerektiğini düşünmekteyiz.

\section{Conflict of Interest}

No conflict of interest was declared by the authors.

Peer-review: Externally peer-reviewed.

\section{Author Contributions}

Concept - B.S., E.G.; Design - Z.Ö., S.E.; Supervision - B.K.; Funding F.M.Y.; Materials - B.S., E.G.; Data Collection and/or Processing - B.S., E.G., Z.Ö.; Analysis and/or Interpretation - Z.Ö.; Literature Review F.M.Y.; Writer - E.G., Z.Ö.; Critical Review - B.K.

\section{Çıkar Çatışması}

Yazarlar herhangi bir çıkar çatışması bildirmemişlerdir.

\section{Hakem değerlendirmesi: Dış bağımsız.}

\section{Yazar Katkıları}

Fikir - B.S., E.G.; Tasarım - Z.Ö., S.E.; Denetleme - B.K.; Kaynaklar - F.M.Y.; Malzemeler - B.S., E.G.; Veri toplanması ve/veya işlemesi - B.S., E.G., Z.Ö.; Analiz ve/veya yorum - Z.Ö.; Literatür taraması - F.M.Y.; Yazıyı yazan - E.G., Z.Ö.; Eleştirel İnceleme - B.K.

\section{Kaynaklar}

1. Beaver AC, Cheatham ML. Life-Threatening Nail Gun Injuries. The Am Surg 1999: 65: 13-6.

2. Guo LR, Myers ML. Penetrating cardiac injury: the nail gun, a potentially dangerous tool. Can J Surg 2008; 51: 7-8.

3. Jodati A, Safaei N, Mehrnoush T, Kazemi B. A unique nail gun injury to the heart with a delayed presentation. Interact CardioVasc Thorac Surg 2011; 13: 363-5. [CrossRef]

4. Temple AD, Fesmire FM, Seaberg DC, Severance HW. Cardiac injury due to accidental discharge of nail gun. J Emerg Med Printing.

5. Lipscomb HJ, Dement JM, Nolan J, Patterson D, Li L. Nail hun injuries in residental carpentry: lessons from active injury surveillance. Injury Prevention 2003; 9: 20-4. [CrossRef]

6. Pierpont YN, Pappas-politis E, Naidu DK, Salas RE, Johnson EL, Payne WG. Nail-gun injuries to the hand. Eplasty 2008; 8: 52.

7. Rofail M, Lee LR, Lee GA, Todd B. Suicide-related perforating injury of globe with nail gun. Clin Experiment Ophthalmol 2005; 33: 294-5. [CrossRef]

8. Wang LT, Chen CJ, Jao SW, Yu JC, Sun GH, Hsieh DS. Pneumatic nail gun injury complicated with bladder penetration and occult jejunum perforation. J Med Sci 2008; 28: 45-8. 
9. Hussey K, Knox D, Lambah A, Curnier AP, Holmes JD, Davies M. Nail gun injuries to the hand. J Trauma 2008; 64: 170-3. [CrossRef]

10. Lipscomb HJ, Nolan J, Petterson D, Dement JM. Continued progress the prevention of nail gun injuries among apprentice carpenters: what will it take to see wider spread injury reductions? J Safety Res 2010; 41:241-5. [CrossRef]
11. Lipscomb HJ, Nolan J, Patterson D, Dement JM. Prevention of traumatic nail gun injuries in apprentice carpenters: Use of population-based measures to monitor intervention effectiveness. Am J Ind Med 2008; 51: 719-27. [CrossRef]

12. Dement JM, Lipscomb H, Li L, Epling C, Desai T. Nail gun injuries among construction workers. Appl Occup Environ Hyg 2003; 18: 374-83. [CrossRef] 